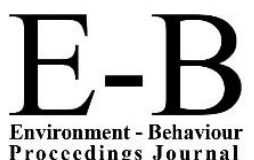

Environment - Behaviour
AIVCE-BS-1, 2020ShahAlam

https://www.amerabra.org; https://fspu.uitm.edu.my/cebs; https://www.emasemasresources.com/ AMEABRA International Virtual Conference on Environment-Bahaviour Studies, $1^{\text {st }}$ Series cE-Bs, FSPU, Universiti Teknologi MARA, Shah Alam, 24 Jun 2020

\section{e-IPH}

- International Publishing House Ltd. United Kingdom

\title{
Understandability and Actionability of Web-based Education Materials on Hypertension Management
}

\author{
Mohd Ramadan Ab Hamid, Mastura Mohd Isamudin, \\ Fatimah Najihah Baderol Allam, Siti Sabariah Buhari \\ ${ }^{1}$ Centre of Nutrition and Dietetics, Faculty of Health Sciences, \\ Universiti Teknologi MARA, Selangor, Malaysia
}

ramadan7230@gmail.com, mastura.mohdisamudin@gmail.com, fatimahnajihah.ba@gmail.com, sabariahuitm6204@uitm.edu.my Tel: +60167123422

\begin{abstract}
Hypertension websites are widely and easily accessible. This study aims to assess the understandability and actionability of hypertension websites. Eight websites that met the inclusion criteria were included. Eight experts were appointed to evaluate the websites using PEMAT instrument. The overall mean scores for understandability and actionability were $76.08 \%$ and $52.83 \%$ respectively. One website did not meet the criteria for understandability (score of $\geq 70 \%$ ), while almost all materials failed to meet the criteria for actionability (score of $\leq 70 \%$ ). In conclusion, this study provides evidence that many of the available hypertension websites can be easily understood but are less actionable.
\end{abstract}

Keywords: Hypertension; Health promotion; Internet; Website quality

eISSN: 2398-42870 2020. The Authors. Published for AMER ABRA cE-Bsby e-International Publishing House, Ltd., UK. This is an open access article under the CC BYNC-ND license (http://creativecommons.org/licenses/by-nc-nd/4.0). Peer-review under responsibility of AMER (Association of Malaysian Environment-Behaviour Researchers), ABRA (Association of Behavioural Researchers on Asians) and cE-Bs (Centre for Environment-Behaviour Studies), Faculty of Architecture, Planning \& Surveying, UniversitiTeknologi MARA, Malaysia.

DOI: https://doi.org/10.21834/ebpj.v5i14.2230

\section{1,0 Introduction}

Early intervention and effective patient education to manage hypertension can decrease the complications of uncontrolled blood pressure (Mohsen Ibrahim, 2018). Patients should have high health literacy level to optimise the medical treatment for hypertension. Health literacy can be defined as the "degree to which individuals have the capacity to entail the knowledge, motivation, and competences to access, understand, appraise, and apply information in everyday life to make judgments and decisions in terms of health care, disease prevention, and healthy behaviours that maintain and promote quality of life throughout the life course (Sørensen et al., 2012). The Malaysia National Health Morbidity Survey in 2015 reported that the level of health literacy among Malaysian was only $6.6 \%$ (Abd Kadir et al., 2015). This should be alarming because individuals with low health literacy have poorer engagement with health care services and could result in lower knowledge of chronic disease (Lee, Wong \& Lee, 2020).

High level of health literacy will increase patients' self-efficacy to optimise the management of hypertension. Thus, materials for patient education (PEM) need to be made easy to obtain, process, understand and apply. In other words, the materials should not be overloaded with information (Cajita, Rodney, Xu, Hladek \& Han, 2017). Also, PEM needs to be easily understood by a broad audience to facilitate the public of diverse backgrounds at all levels of health literacy to know what actions to take (Yiu, Ng, Lee \& Bajorek, 2020).

The ease of access, immediacy and interactive quality is changing the way people seek health information using the Internet (Wang, Shi \& Kong, 2020). The Internet has become an indispensable medium for the delivery of patient education. Rahim, Ibrahim, Salim \& Ariffin (2019) reported that the public in Malaysia search for online health information related to their health problem. The widespread accessibility of inaccurate and possibly harmful health information on the Internet could potentially limit health literacy (Waring, McManus, Amante, Darling \& Kiefe, 2018). While the Internet provides easy access to health information, it is not guaranteed that the

eISSN: 2398-4287C 2020. The Authors. Published for AMER ABRA cE-Bsby e-International Publishing House, Ltd., UK. This is an open access article under the CC BYNC-ND license (http://creativecommons.org/licenses/by-nc-nd/4.0/). Peer-review under responsibility of AMER (Association of Malaysian Environment-Behaviour Researchers), ABRA (Association of Behavioural Researchers on Asians) and cE-Bs (Centre for Environment-Behaviour Studies), Faculty of Architecture, Planning \& Surveying, UniversitiTeknologi MARA, Malaysia.

DOI: https://doi.org/10.21834/ebpj.v5i14.2230 
information can be easily understood or practised. Therefore, this study aims to evaluate the understandability and actionability of online health information about hypertension. The specific objectives of this study are to determine the understandability and actionability of hypertension information found online and to compare understandability and actionability of the hypertension information among the different types of websites (government vs non-government).

\subsection{Literature Review}

Hypertension is a non-communicable disease marked by a chronic increase in systolic blood pressure (World Health Organization, 2013). The prevalence of hypertension in Malaysia was $28.2 \%$ among people aged 18 years and older, and $40 \%$ among people aged above 30 (Chow et al., 2019). There was a significantly lower quality of treatment and control in the rural area than the urban area among hypertensive patients (Abdul-Razak et al., 2016). Lower educational attainment and/or lower literacy were significant independent predictors of poorer hypertension knowledge. Therefore, good quality of online health information, mainly information that is highly understandable and actionable, could increase health literacy among patients. Understandability is defined as the way health information was written that can be understood by consumers regardless of their background and different levels of health literacy; and, and actionability can be defined as the way information was written that allows the users to easily determine what they need to do when they have the disease, according to the information presented (Keçeci, Toprak \& Kiliç, 2019; Shoemaker, Wolf \& Brach, 2014).

The Internet has changed the way information is shared and accessed, which make information retrieval easier and faster than before. There are 4.54 billion (59\%) of Internet users worldwide. In Malaysia, up to January 2020, there are 26 million Internet users, an addition of almost one million users from the year 2019, showing an increasing trend. Google.com was ranked number 1 search engine, followed by Yahoo.com, in term of the most-visited websites in Malaysia (Simon, 2020). A survey on health information behaviour in Malaysia revealed that $97.5 \%$ of the participants have searched for online patient education materials (Tobi, Masrom \& Rahaman, 2017). Previous studies showed seeking online health information have the potential to help improve the medical treatment such as pharmacological awareness (Yiu et al., 2020) and hypertension management (Visla, Shatola, Wisner \& Shaikh, 2019).

Past studies of online health information tend to simply report the proportions of inaccurate information to indicate the prevalence of undesirable information or the risk of encountering misinformation online (Shim \& Jo, 2020). Bad health information can be highly detrimental as patients might trust the wrong information leading to conflict with appropriate medical practices (Tonsaker, Bartlett \& Trpkov, 2014). Patients' decision based on low-quality information (e.g. information that is incomplete, inaccurate or biased) might bring harmful effects, such as delayed treatment or extreme anxiety. It later may even increase public vulnerability (Sbaffi \& Rowley, 2017).

\subsection{Methodology}

\subsection{Research design}

A descriptive cross-sectional study was conducted to evaluate the overall quality of information, specifically the understandability and actionability of websites or blogs that provide information related to hypertension in Malaysian Internet space.

\subsection{Evaluation of the actionability and understandability}

Understandability and actionability were measured using the Patient Education Material Assessment Tool for Print Materials (PEMATP) (Shoemaker et al., 2014). The use of PEMAT was recommended to evaluate patient education materials (Lipari, Berlie, Saleh, Hang $\&$ Moser, 2019). This instrument comprises of 19 items on understandability and seven items on actionability. Binary scale (1, agree; 0 , disagree) was used to score each item in both questionnaires. Overall scores for understandability and actionability was determined by adding the points and dividing the total possible points (excluding the items that score as N/A or Not Applicable) and multiplying the results by 100 (score range, $0 \%-100 \%$ ). The score that exceeds $70 \%$ will be classified as highly understandable or highly actionable (Shoemaker et al., 2014). Eight experts from the Faculty of Health Sciences, Universiti Teknologi MARA and Ministry of Health, Malaysia were appointed as evaluators. The interrater reliability was measured using Intra-Class Correlation; and showed a good score (0.88) for understandability and moderate (0.69) for actionability (Koo \& Li, 2016)

\subsection{Data collection}

The websites were determined using five search engines, namely Google, Yahoo, Bing, Ask.com, and DuckDuckGo. The keywords "hypertension", "high blood pressure" and combination of keywords "hypertension and treatment", "high blood pressure and treatment" were used; and Malay language equivalences of these keywords were also used. At every search, the top five pages of the results from each search engine were retrieved for further analysis. The use of five search engines was to ensure as many as possible websites were selected in the study. Google search was used as a reference due to it being the most popular search engine among users in Malaysia (Simon, 2020), and all the repeated websites from the other four search engines were analysed only once. Figure 1 shows the websites search process. 


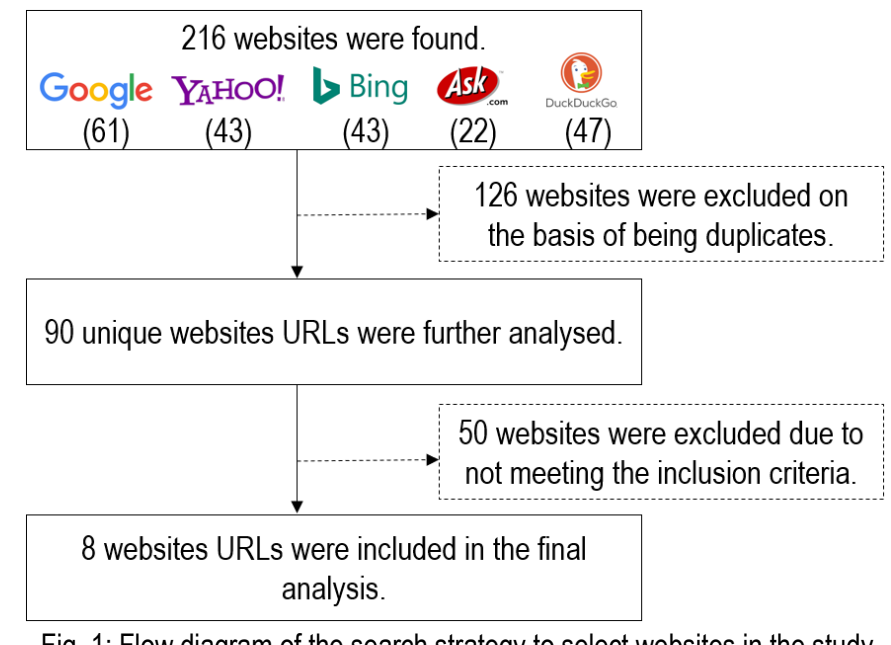

The selected websites in this study were categorised into government and non-government. The government website is defined as any website that is produced or written by the government or ministry of education. This type of website usually has web address that ends with .gov or .edu. The non-government website is defined as any website that is written by private sectors like any private company to promote their business and any blog that is written by an individual by using evidence-based information.

\subsection{Data Analysis}

Descriptive statistics are reported as means and standard deviations. Mann-Whitney $\mathrm{U}$ test was used to compare the understandability and actionability scores among the two types of websites. Statistical analyses were performed using SPSS version 20.

\subsection{Ethical approval}

This study was approved by the UiTM Research Ethics Committee with the reference number 600-IRMI (5/1/6).

\subsection{Result}

Overall, eight websites were included in this study (Figure 2). The overall result for understandability and actionability are presented in Table 1.

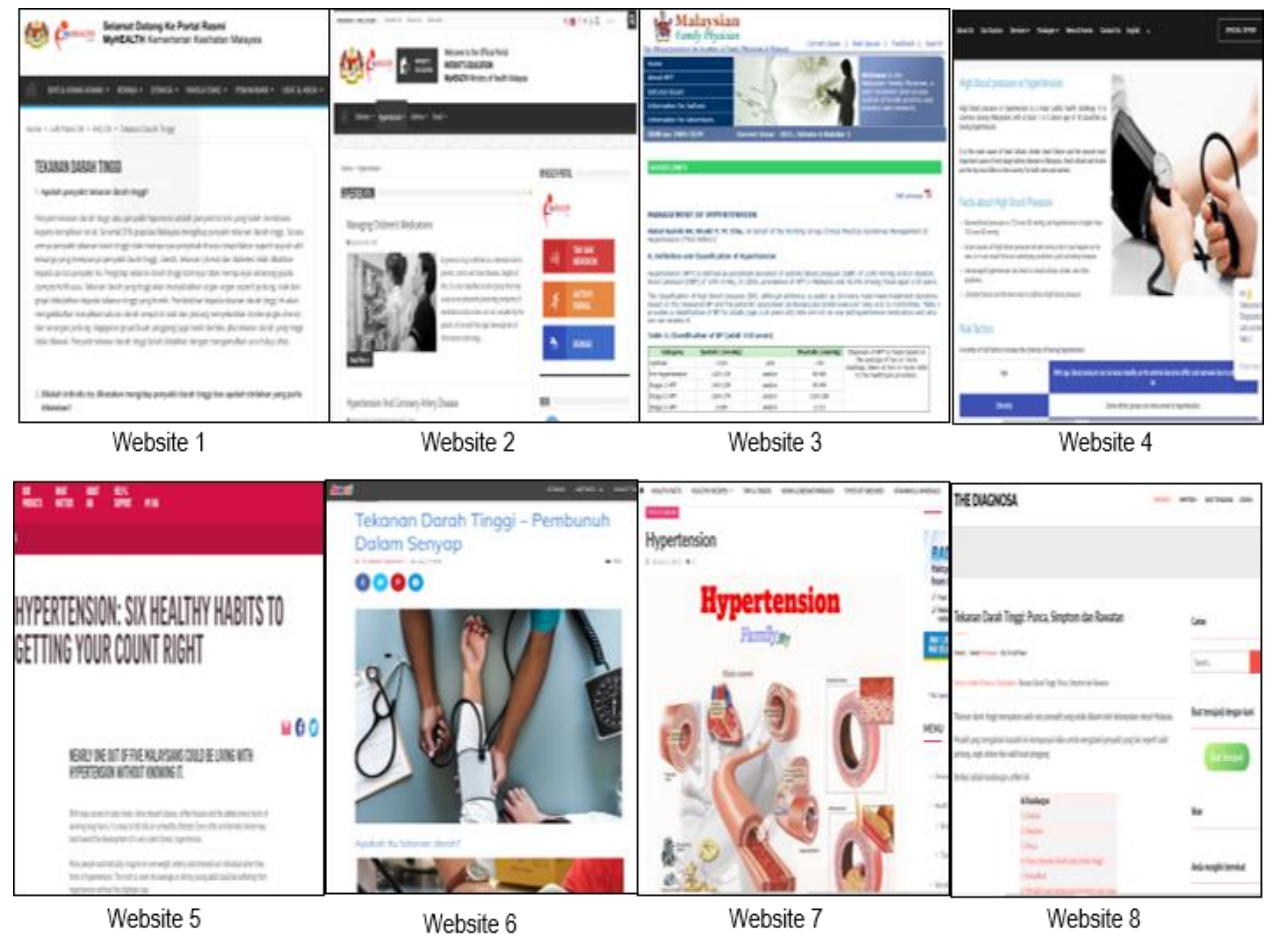

Fig. 2: Front page of the eight websites in the study 
The PEMAT scores for understandability and actionability of each website are summarized in Table 1 . The overall mean scores for understandability and actionability were $76.08 \%$ and $52.83 \%$ respectively. Only one of all websites did not meet the criteria for understandability (score of $\geq 70 \%$ ), while almost all $(n=7)$ materials failed to meet the criteria for actionability (score of $\leq 70 \%$ ). Government Website 2 scored highest for understandability (94.81\%) and actionability (82.50\%). The non-government Website 7 scored lowest for understandability (59.87\%) and Website 6 for actionability (35\%). A Mann-Whitney $\mathrm{U}$ test was run to determine if there were differences in understandability and actionability scores between government and non-government websites. Distribution of the understandability and actionability scores for government and non-government websites were not similar, as assessed by visual inspection; therefore, results were interpreted using mean rank (Dinneen \& Blakesley, 1973). Understandability scores for government (mean rank=5.0) were higher than non-government (mean rank=4.33) but were not statistically significantly different, $\mathrm{U}=5.0, \mathrm{z}=-0.33$, $\mathrm{p}=0.86$. Actionability scores for government (mean rank=6.75) were also higher than non-government (mean rank=3.75) but not statistically different, $U=1.50, z=-1.51, p=0.14$ (Table 2).

Table 1. Means percentage for the overall evaluation of hypertension websites

\begin{tabular}{|c|c|c|c|c|c|c|c|}
\hline 2 & \multicolumn{4}{|c|}{ http://pendidikanpesakit.myhealth.gov.my/en/category/hypertension/ } & G & 94.81 & 82.50 \\
\hline 4 & \multicolumn{4}{|c|}{$\begin{array}{l}\text { https://lifecarediagnostic.com/did-you-know-1-in-3-malaysian-suffers-from- } \\
\text { hypertension/ }\end{array}$} & NG & 86.39 & 54.29 \\
\hline 5 & \multicolumn{4}{|c|}{$\begin{array}{l}\text { https://www.aia.com.my/en/what-matters/health-wellness/hypertension-Six-Healthy- } \\
\text { Habits-to-Getting-Your-Count-Right.html }\end{array}$} & NG & 78.77 & 48.57 \\
\hline 7 & \multicolumn{4}{|c|}{ https://health.family.my/types-of-diseases/hypertension } & NG & 59.87 & 43.10 \\
\hline 8 & \multicolumn{4}{|c|}{ https://thediagnosa.com/tekanan-darah-tinggi-punca-rawatan/ } & NG & 72.77 & 48.45 \\
\hline & \multicolumn{4}{|l|}{ Overall } & & 76.08 & 52.83 \\
\hline \multicolumn{8}{|c|}{ "Acronym: U, Understandability; A, Actionability; G: Government, NG: Non-Government } \\
\hline \multicolumn{8}{|c|}{ Table 2. Comparison scores between government and non-government websites } \\
\hline Understandability & 5.00 & 2 & 4.33 & 6 & 5.00 & -0.33 & 0.86 \\
\hline Actionability & 6.75 & 2 & 3.75 & 6 & 1.50 & -1.51 & 0.14 \\
\hline
\end{tabular}

There was variation in the mean scores for each of the PEMAT-Understandability items (Figure 3). The mean scores were higher on seven items, namely: [item 3] everyday language used, [item 4] medical terms defined and used sparsely, [item 5] use of active voice, [item 7] no calculation, [item 8] chunking of info, [item 9] use of informative headers and [item 10] info presented in a logical sequence. Conversely, the websites scored lower on the scale 1-3 out of 5 on the following four items: [item 13] use of visual aids, [item 14] visual aids that reinforce content, [item 15] clear titles/captions on visual aids and [item17] use of simple table.

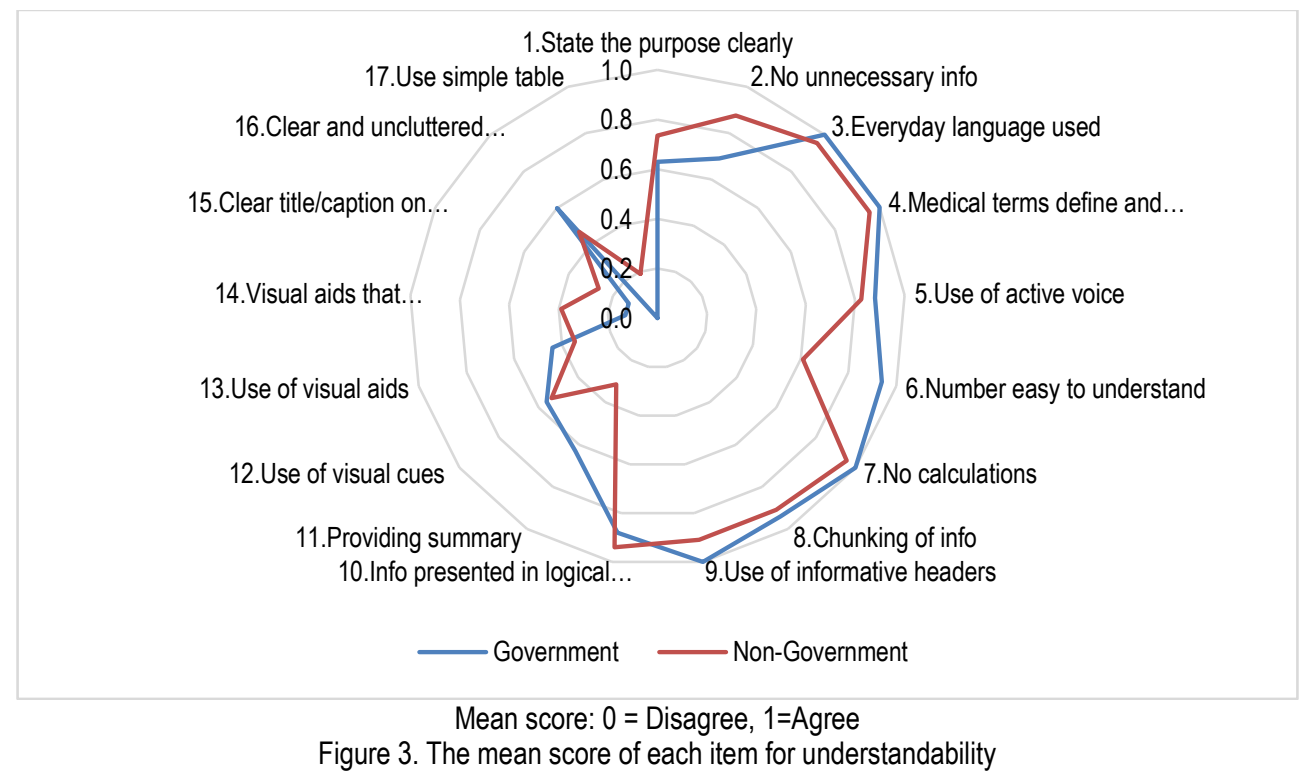

The mean scores for each of the PEMAT-Actionability items also varied (Figure 4). Most of the websites identified at least one action that the user can take [item 1], addressed the user directly [item 2] and broke instruction into manageable steps [item 3]. However, the 
majority of the websites did not explain how to use charts, tables etc. [item 6] and did not use visual aids to make it easier for the user to follow their instructions [item 7].

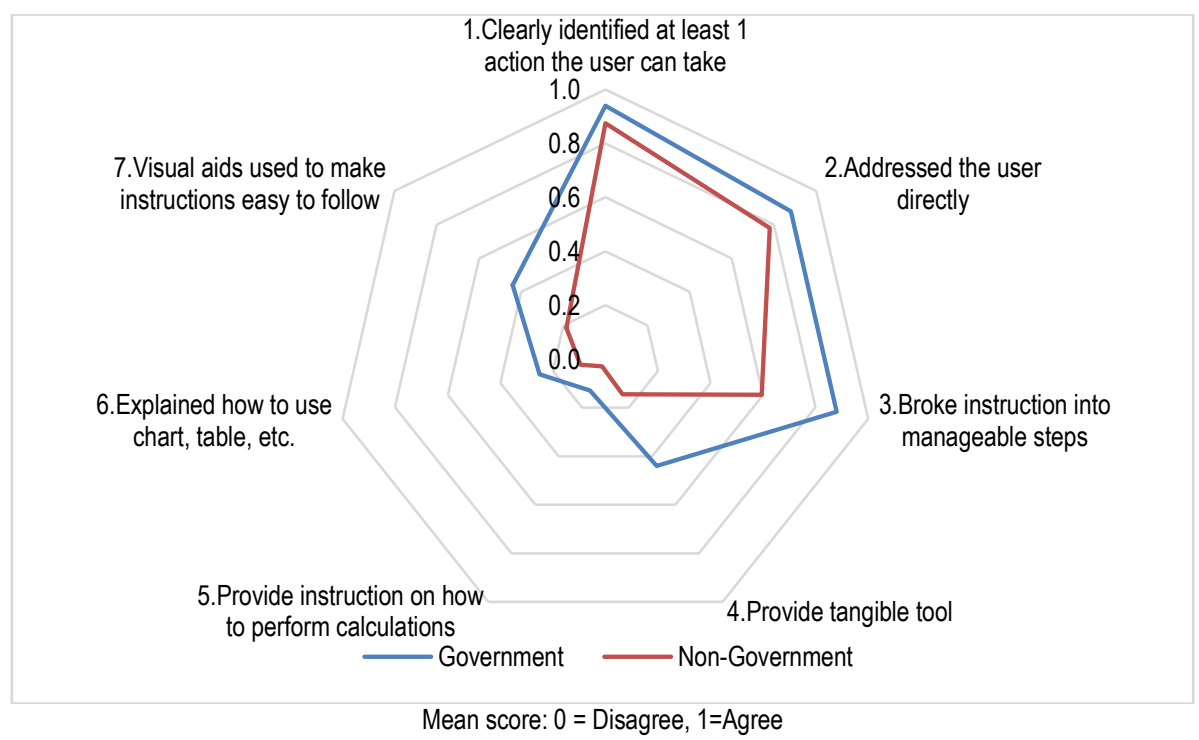

Figure 4. The mean score of each item for actionability

\subsection{Discussion}

This study shows on overall the websites were highly understandable as the scores exceed 70\% (Shoemaker et al., 2014). All websites contain necessary information without being overloaded and state the purpose of the information clearly. It is vital for the educational materials need to mention the outcomes of learning because patients' health-seeking behaviour is viewed a purposeful and goal-oriented activity, rather than passive exposure to information (Sherif, Pluye, Thoër \& Rodriguez, 2018). Other than that, these websites also delivered information using common or plain language. Plain language is important to ensure health resources are written at a literacy level that is as universally accessible as possible. Next, most of these websites did chunk the information into sections and provided informative headers for every section, which make it easier for readers to focus on what information was important on the websites. These websites also present the information in a logical sequence which follows an intuitive flow and might contribute to high understandability scores (Fajardo, Balthazaar, Zalums, Trevena \& Bonner, 2019).

In contrast, most of the websites scored lower on the use of visuals, graphs or tables. The combination of text, audio and visual formats in the websites provide choices to cater to users' preferences and learning styles. The attractive visual guide is important; the look and feel of a website do affect the users and are beneficial for patients with limited health literacy (Yiu et al., 2020). High understandability would benefit the users to assist them regarding their health concern (Palotti, Zuccon \& Hanbury, 2019) and on the management of chronic diseases correctly.

The overall mean for actionability of the websites was $52.82 \%$ which was slightly higher than those reported in another study (49\%) (Zellmer, Zimdars, Parker \& Safdar, 2015). Nevertheless, this result still portrays these websites as less actionable because the score should be more than $70 \%$ to be considered actionable (Shoemaker et al., 2014). This finding shows that almost all websites need to improve on the actionability. The lower score of actionability is due to the websites' failure to provide enough tangible tools such as menu planners, and checklist. that would help users to take action. Also, most websites did not provide enough visual aids to make the instructions easier to be followed by users. Offering some relevant tools in websites, such as instructional videos, will empower users to apply the information they learnt into an actual action (Cajita et al., 2017). The use of visual aids, such as checklists makes it easier for patients to act on instructions (Yiu et al., 2020).

Government websites tend to have a higher score for both understandability and actionability when compared with the nongovernment websites. In the United States, the enactment of Plain Writing Act of 2010, requires any government agencies to use communication that is clear for the public to understand and practice (Cajita et al., 2017). However, in Malaysia, the possible explanation is the clinicians or authors from the government may consider the broad background of users. Other than that, most of the government websites have better reliability compared to the non-government websites. However, the differences between these two types of websites were not statistically significant due to small sample size. The higher score for government websites could be due to being the official government health portals that function to disseminate health information to the public and to be references to clinicians. People may prioritize government websites when they look for health information. It could be due to the government has lots of available resources that include funds and human resource to maintain and update the websites. In contrast the lower actionability scores may impair the patients' standard of care. Understanding the $f$ the disease must come together with the practical guidance on how to manage the disease. Missing one of these components could reduce the benefits of online patient education materials to the users. 
PEMAT questionnaire has been used widely and reported in many studies on the evaluation of understandability and actionability of patient education materials. In this study, the reason for choosing PEMAT instrument to evaluate the websites is the ability of the tool to deliver direct information on how well the content of the material, reliability of visual aids, word choice, appropriate layout and design, and delivery approaches of the materials. The instrument also provides suggestions to improve educational materials, such as by always using the active voice, defining all medical terminology, and having a summary of key points discussed at the end of the article (Shoemaker et al., 2014). The results can be used as references to improve the websites in the future.

An important limitation of this study is that understandability and actionability do not imply the factual accuracy of online patient education materials. This study also did not address if the websites are comprehensive in their scope or adhere to evidence-based practice guidelines.

\subsection{Conclusion\& Recommendations}

In conclusion, this study provides evidence that many of the available websites can be easily understood but less actionable. Patient education materials should not only be a source of information that is easily understood but should also allow patients to take action for managing their disease. Clinicians and patients would benefit greatly using materials that include visual aids, tangible tools and summaries. The development of future patient education materials should be with the intention to increase the understandability and with special emphasis on actionability. Also, it would be important to incorporate patients' feedback to determine the usefulness of patient education materials. Future studies could evaluate the quality of online health information. The fast changes of health information from time to time and updates on the websites were also part of the limitation of this study. The result may not be relevant in the future; thus, frequent assessment should be conducted. Also, this study explored websites available in English and Malay language only, therefore limiting the selection of the websites.

\section{Acknowledgement}

This study was supported by a grant from the Ministry of Higher Education, Malaysia (reference number FRGS/1/2019/SS06/UiTM/03/6 and 600-IRMI/FRGS 5/3 [448/2019]). The authors would like to express their gratitude to the Ministry for this financial support and to the experts who gave a full commitment to this study. The data reported in this paper are those of the authors and are independent of the funding source.

\section{References}

Abd Kadir, A. B., Abdul Aiman, A. G., Abu Bakar, R., Ahmad Ali, Z., Ahmad Nadzri, J., Chandran, A., \& Asmah, R. (2015). National Health and Morbidity Survey 2015. Institute for Public Health.

Abdul-Razak, S., Daher, A. M., Ramli, A. S., Ariffin, F., Mazapuspavina, M. Y., Ambigga, K. S., Miskan, M., Abdul-Hamid, H., Mat-Nasir, N., Nor-Ashikin, M.N.K., Ng, K.K., Nawawi, H., \& Yusoff, K. (2016). Prevalence, awareness, treatment, control and socio demographic determinants of hypertension in Malaysian adults. BMC Public Health, 16(1), 1-10.

Cajita, M. I., Rodney, T., Xu, J., Hladek, M., \& Han, H. R. (2017). Quality and health literacy demand of online heart failure information. Journal of Cardiovascular Nursing, 32(2), $156-164$.

Chow, Z. Y., Jun, S. M., Ching, S. M., Tan, C. H., Lee, K. W., Devaraj, N. K., Chia, Y. C. (2019). Prevalence, awareness and control of hypertension in Malaysia $1980-$ 2017: A Systematic Review and Meta-Analysis. BioRxiv, 625004.

Dinneen, L. C., \& Blakesley, B. C. (1973). Algorithm AS 62: A Generator for the Sampling Distribution of the Mann- Whitney U Statistic. Applied Statistics, 22(2), 269. Diviani, N., Van Den Putte, B., Giani, S., \& Van Weert, J. C. M. (2015). Low health literacy and evaluation of online health information: A systematic review of the literature. Journal of Medical Internet Research.

Hamzah, M. R., Mohamad, E. M. W., Abdullah, M. Y., \& Hadi Ayub, S. (2015). Scenario on health information seeking in Malaysia: A systematic review. Journal of Human Development and Communication, 4 (2016), 7-20.

Keçeci, A., Toprak, S., \& Kiliç, S. (2019). How Effective Are Patient Education Materials in Educating Patients? Clinical Nursing Research, 28(5), 567-582.

Koo, T. K., \& Li, M. Y. (2016). A Guideline of Selecting and Reporting Intraclass Correlation Coefficients for Reliability Research. Journal of Chiropractic Medicine, 15(2), $155-163$.

Lee, J. Y., Wong, C. P., \& Lee, S. W. H. (2020). m-Health views and perception among Malaysian: findings from a survey among individuals living in Selangor. MHealth, $6(2019), 6-6$.

Lipari, M., Berlie, H., Saleh, Y., Hang, P., \& Moser, L. (2019). Understandability, actionability, and readability of online patient education materials about diabetes mellitus. American Journal of Health-System Pharmacy, 76(3), 182-186.

Mohsen Ibrahim, M. (2018). Hypertension in Developing Countries: A Major Challenge for the Future. Current Hypertension Reports, 20(5).

Palotti, J., Zuccon, G., \& Hanbury, A. (2019). Consumer Health Search on the Web: Study of Web Page Understandability and Its Integration in Ranking Algorithms. Journal of Medical Internet Research, 21(1), e10986. 
Rahim, A. I. A., Ibrahim, M. I., Salim, F. N. A., \& Ariffin, M. A. I. (2019). Health information engagement factors in Malaysia: A content analysis of facebook use by the ministry of health in 2016 and 2017. International Journal of Environmental Research and Public Health, 16(4).

Sbaffi, L., \& Rowley, J. (2017). Trust and credibility in web-based health information: A review and agenda for future research. Journal of Medical Internet Research. Sharma, N., Tridimas, A., \& Fitzsimmons, P. R. (2014). A readability assessment of online stroke information. Journal of Stroke and Cerebrovascular Diseases, 23(6), 1362-1367.

Sherif, R. El, Pluye, P., Thoër, C., \& Rodriguez, C. (2018). Reducing negative outcomes of online consumer health information: Qualitative interpretive study with clinicians, librarians, and consumers. Journal of Medical Internet Research, 20(5), 1-16.

Shim, M., \& Jo, H. S. (2020). What quality factors matter in enhancing the perceived benefits of online health information sites? Application of the updated DeLone and McLean Information Systems Success Model. International Journal of Medical Informatics, 137(September 2019), 104093

Shoemaker, S. J., Wolf, M. S., \& Brach, C. (2014). Development of the Patient Education Materials Assessment Tool (PEMAT): A new measure of understandability and actionability for print and audiovisual patient information. Patient Education and Counseling, 96(3), 395-403.

Simon, K. (2020). Digital 2020: Malaysia. Retrieved April 26, 2020, from https://datareportal.com/reports/digital-2020-malaysia

Sørensen, K., Van Den Broucke, S., Fullam, J., Doyle, G., Pelikan, J., Slonska, Z., \& Brand, H. (2012). Health literacy and public health: A systematic review and integration of definitions and models. BMC Public Health.

Tobi, S. N. M., Masrom, M., \& Rahaman, S. A. S. A. (2017). Healthcare portals and the usage trends in Malaysia. Adv. Science Letters, 23(4), 2857-2860.

Visla, J., Shatola, A., Wisner, D. H., \& Shaikh, U. (2019). Understandability and Actionability of Online Information on Hypertension. Population Health Management, 22(4), 369 .

Wang, X., Shi, J., \& Kong, H. (2020). Online Health Information Seeking: A Review and Meta-Analysis. Health Communication, 00(00), 1-13.

Waring, M. E., McManus, D. D., Amante, D. J., Darling, C. E., \& Kiefe, C. I. (2018). Online health information seeking by adults hospitalized for acute coronary syndromes: Who looks for information, and who discusses it with healthcare providers? Patient Education and Counseling, 101(11),

World Health Organization. (2013). A Global Brief on Hypertension World; Silent Killer, Global Health Crisis. World Health Organization.

Yiu, A., Ng, K. K., Lee, V. W., \& Bajorek, B. V. (2020). Evaluating the Understandability and Actionability of Web-Based Education Materials for Patients Taking Nonvitamin K Oral Anticoagulants. Therapeutic Innovation and Regulatory Science, 54(2), 476-483.

Zellmer, C., Zimdars, P., Parker, S., \& Safdar, N. (2015). Evaluating the usefulness of patient education materials on surgical site infection: A systematic assessment. American Journal of Infection Control, 43(2), 167-168. 